\title{
Pengenalan Aplikasi Pembelajaran Bahasa Isyarat i-Chat untuk Anak Berkebutuhan Khusus di Panti Asuhan Semara Putra Klungkung
}

\author{
${ }^{1 *}$ Paula Dewanti, ${ }^{2}$ Indriyani, ${ }^{3}$ Kadek Vishnu Vedamurthi \\ Institut Teknologi dan Bisnis STIKOM Bali \\ *Email: paula_dewanti@stikom-bali.ac.id
}

\begin{abstract}
RINGKASAN
i-CHAT (I Can Hear and Talk) adalah aplikasi berbasis komputer yang dirancang untuk membantu orang, terutama anak-anak dengan gangguan pendengaran. Aplikasi ini dapat membantu pengguna untuk menguasai kemampuan liguistik. Aplikasi ini telah dikembangkan oleh Telkom Divisi Digital Service yang merupakan perwujudan program Corporate Social Responsibility (CSR) Telkom. Bertempat di Panti Asuhan Semara Putra Klungkung, kegiatan Pengenalan Aplikasi Pembelajaran Bahasa Isyarat i-Chat dilakukan dengan metode penyuluhan, praktik langsung, serta tanya jawab kepada peserta pelatihan. Fokus permasalahan yang menjadi perhatian adalah bagaimana teknologi dapat dimanfaatkan sebagai media pembelajaran anak asuh panti yang memiliki salah satu kebutuhan khusus, yaitu ABK Tuna Rungu. Melalui kegiatan Pengabdian Masyarakat ini, tim pelaksana bersama Panti Asuhan Semara Putra dapat mengambil bagian dalam pemanfaatan Ilmu Pengetahuan dan Teknologi untuk memajukan kesejahteraan masyarakat dan mencerdaskan kehidupan bangsa, khususnya Anak Berkebutuhan Khusus.
\end{abstract}

Kata kunci : anak berkebutuhan khusus, i-CHAT, pengabdian masyarakat

\section{SUMMARY}

i-CHAT (I Can Hear and Talk) is a computer based application designed to help people, especially children with hearing impairment to master their linguistic abilities through multimedia-based sign language learning developed by the Telkom Digital Service Division and is an embodiment of the program Telkom's Corporate Social Responsibility (CSR). Took a place in Semara Putra Klungkung Orphanage, Bali, the Community Service focused in Introduction of the i-Chat Sign Language Learning Application were carried out, used counseling methods, best practice, as well as simple questions and answers session to the participants. The focus of concern is how technology can be utilized as a learning medium for children with special needs with hearing impairs. The Community Service expected to take part in the utilization of Science and Technology to advance the welfare of the community and educate the nation's life, especially Children with Special Needs.

Key words: children with special needs, community service, $i$-CHAT 


\section{PENDAHULUAN}

\section{A. Panti Asuhan Semara Putra Klungkung}

Panti Asuhan Semara Putra berlokasi di Jalan Dewi Sartika No. 5, Semarapura, Klungkung, Panti ini, secara keseluruhan, memiliki anak asuh berjumlah 125 dengan perincian sebagai berikut:

- 90 anak tinggal di luar panti (tidak menetap) yang duduk dijenjang studi SD 84 anak dan SMA 6 anak.

- 35 anak tinggal di dalam panti dengan jenjang studi SMP 8 orang, SMA 21 orang, dan SD 6 orang.

Anak-anak penghuni panti, berusia antara 6 hingga 18 tahun, di mana mereka rata-rata masih mempunyai orang tua, baik orang tua yang utuh maupun orang tua tunggal.

Panti Asuhan Semara Putra memiliki ABK yang meliputi Tuna Grahita, Tuna Rungu, Autis, Down Syndrome dan Hiperaktif. Pengelompokan ABK didasarkan pada jenis disabilitas dan bukan tergantung dari usia mereka. Pihak pengelola panti akan mengembalikan anak asuh mereka kepada keluarga dan masyarakat secara penuh apabila dianggap telah memiliki kemampuan untuk mandiri. Keterlibatan keluarga dan masyarakat dianggap penting untuk perkembangan mental ABK dan pembelajaran untuk keluarga maupun masyarakat di dalam menerima ABK. Terdapat 4 ABK Tuna Rungu yang mengikuti kegiatan pelatihan dengan fokus dan semangat.

Di bawah naungan Yayasan Kripana Putra Dharma yang diketuai oleh Ibu Ni Made Gunasih, Panti Asuhan Semara Putra berdiri sejak tahun 1985. Panti asuhan ini telah berjasa dan masih terus berusaha untuk membina dan menyediakan tempat tinggal di asrama kepada anak-anak berkebutuhan khusus, terlantar, dan anakanak dari keluarga kurang mampu.

\section{B. Anak Berkebutuhan Khusus}

Ada beberapa anak berkebutuhan khusus di bawah naungan Panti Asuhan Semara Putra, Klungkung.
Secara umum dapat digambarkan bahwa Anak Berkebutuhan Khusus adalah anak atau individu yang memiliki karakteristik berbeda dengan anak pada umumnya, dimana anak tersebut memiliki karakterisitik fisik, emosional dan intelektual yang berbeda dengan anak lainya yang dipandang normal oleh masyarakat umum (Dewanti, 2019). Tuna Rungu adalah anak atau individu yang tidak memiliki kemampuan mendengar. Jadi, anak berkebutuhan khusus dengan ketidakmampuan dalam pendengaran tidak dapat mendengar suara atau bunyi yang dapat membangun interaksi individunya (Abdullah, 2013). Dalam hal ini, pemberian materi pembelajaran dapat dilakukan melalui bahasa isyarat atau dengan gerakan anggota tubuh (Desiningrum, 2017).

Pemerintah menjamin pelaksanaan pendidikan khusus dan pendidikan layanan khusus melalui Undang-Undang No.20 tahun 2003 tentang Sistem Pendidikan Nasional. Lebih lanjut, ketentuan mengenai pelaksanaan pendidikan khusus dan pendidikan layanan khusus sebagaimana dimaksud diatur dengan Peraturan Pemerintah (Perempuan, 2013). Secara keseluruhan, dokumen di atas memberikan jaminan penuh kepada anak berkebutuhan khusus dalam memperoleh pendidikan yang bermutu dan berpartisipasi aktif dalam kehidupan masyarakat (Sujatmoko, 2010).

\section{I-CHAT}

Aplikasi i-CHAT (I Can Hear and Talk) adalah aplikasi pembelajaran bahasa Isyarat, berbasis komputer, yang dirancang untuk Anak Berkebutuhan Khusus dalam pendengaran yang dikemas dalam bentuk multimedia.

i-CHAT yang merupakan Program CSR (Corporate Social Responsibility) PT. Telekomunikasi Indonesia, Tbk yang telah disosialisasikan kurang lebih ke 122 SLB$\mathrm{B}$ di Indonesia.

Hingga saat ini, aplikasi i-CHAT memuat konten untuk 7000 kata dalam 
bentuk video isyarat dan video pengucapan. Aplikasi ini diharapkan dapat bermanfaat bagi komunitas berkebutuhan khusus dalam pendengaran serta orang tua, guru, dan kerabat mereka.

Evaluasi yang telah diperoleh dari kegiatan ini, pemateri merasa perlu untuk terlebih dahulu mendalami Bahasa Isyarat dengan standar yang telah ditentukan sebelum pelaksanaan kegiatan dikarenakan keterbatasan kemampuan pemateri dalam bidang pembelajaran ABK serta keterbatasan dari konten aplikasi i-CHAT itu sendiri.

Aplikasi i-CHAT tersedia untuk Bahasa Isyarat Indonesia \& Malaysia (Melayu). Aplikasi ini mengarahkan pengguna untuk belajar Bahasa Isyarat Indonesia \& Malaysia dan bagaimana mengatur kalimat afirmatif (Yanuardi, 2016).

\section{RUMUSAN MASALAH}

Permasalahan yang ditangani dalam kegiatan Pengabdian Masyarakat ini adalah:

1. Bagaimana teknologi dapat dimanfaatkan sebagai media pembelajaran bagi anak asuh panti yang memiliki salah satu kebutuhan khusus, yaitu ABK dengan Tuna Rungu?

2. Bagaimana Panti Asuhan Semara Putra dapat berbagi informasi dengan masyarakat/dunia luar tentang kegiatan dan keberadaan panti sehingga dapat membuka peluang masyarakat untuk mengenal dan memberikan bantuan untuk keberlanjutan panti?

\section{METODE PELAKSANAAN}

Pengabdian Masyarakat dilakukan dalam bentuk Penyuluhan dan Pelatihan. Kemampuan komunikasi ABK tertentu diamati sehingga pendekatan perorangan dan kecepatan pelatihan disesuaikan dengan kemampuan masing-masing $\mathrm{ABK}$ dengan bantuan koordinator anak asuh panti.

Pengabdian Masyarakat dilaksanakan pada hari Kamis, tanggal 12 Desember
2019. Lokasi Pengabdian Masyarakat adalah Panti Asuhan Semara Putra. Klungkung, Bali yang memiliki jarak kurang lebih $29.8 \mathrm{~km}$ dari lokasi kampus ITB STIKOM Bali, seperti dijelaskan pada Gambar 1. Waktu tempuh berkendara kurang lebih 1 jam dari pusat kota Denpasar, menggunakan kendaraan roda empat atau roda dua.

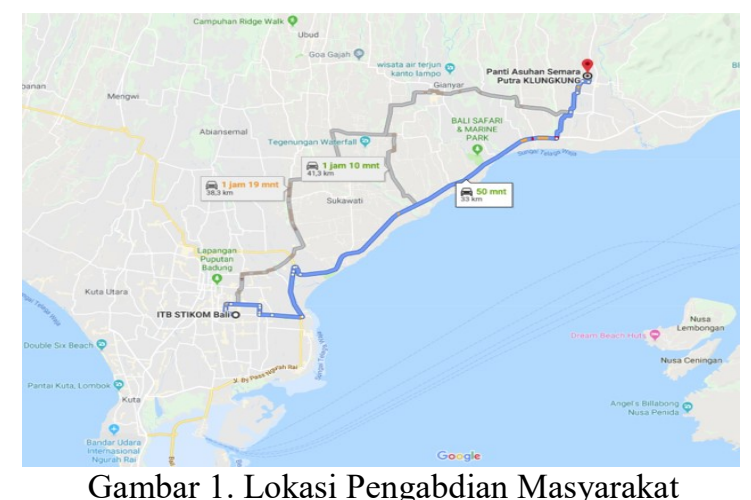

Gambar 1. Lokasi Pengabdian Masyarakat

Berdasarkan analisa awal terhadap situasi yang ada, telah dilaksanakan kegiatan sebagai berikut:

Pelatihan pemanfaatan aplikasi i-CHAT untuk para koordinator anak asuh panti, yang kemudian dilanjutkan kepada penghuni panti secara keseluruhan, termasuk ABK sesuai target dari aplikasi, yaitu ABK Tuna Rungu. Dilakukan PreTest berupa sejumlah pertanyaan sederhana untuk mengukur pemahaman awal penghuni panti tentang bahasa isyarat.

Pelatihan melibatkan penghuni panti lainnya agar mereka mampu berkomunikasi serta turut membimbing rekan mereka yang Tuna Rungu. Di akhir pelatihan, dilakukan Post-Test melalui beberapa pertanyaan yang juga sederhana, untuk mengukur hasil akhir pemahaman para penghuni panti tentang bahasa isyarat.

\section{HASIL DAN PEMBAHASAN}

Observasi awal memberikan informasi bahwa Panti Asuhan Semara Putra telah mendapatkan pelatihan Internet Sehat yang diselenggarakan oleh salah satu Unit Kegiatan Mahasiswa (UKM), pada tahun 
sebelumnya, di mana penulis turut mengambil bagian sebagai pendamping mahasiswa.

Selanjutnya, berdasarkan studi awal pada saat itu, ditemukan bahwa sebagian warga panti telah melek teknologi. Hal tersebut memudahkan tim dalam mengenalkan dan melakukan pelatihan aplikasi i-CHAT. Kegiatan pengenalan aplikasi pembelajaran bahasa isyarat iCHAT untuk anak berkebutuhan khusus di Panti Asuhan Semara Putra Klungkung ini dilakukan dengan metode penyuluhan, praktik langsung, serta tanya jawab kepada peserta pelatihan, bertempat di lokasi Panti. Peserta pelatihan diberikan materi tercetak, setelah pelatihan, sebagai bahan referensi apabila dibutuhkan. Kegiatan pada Pengabdian Masyarakat ini berperan membantu Mitra dalam berkomunikasi dengan anak berkebutuhan khusus (ABK) Tuna Rungu, sekaligus pembelajaran bagi ABK itu sendiri.

Pembelajaran dengan penggunaan multimedia pada aplikasi i-CHAT juga menarik minat dan dapat diterima dengan baik oleh anak-anak panti non-ABK. Pada gambar berikut adalah beberapa cuplikan dari liputan kegiatan Pengenalan dan Pelatihan Aplikasi i-CHAT di Panti Asuhan Semara Putra, Klungkung, Bali. Gambar 2 dan Gambar 3 merupakan sebagian dari materi yang dipaparkan dalam kegiatan ini.

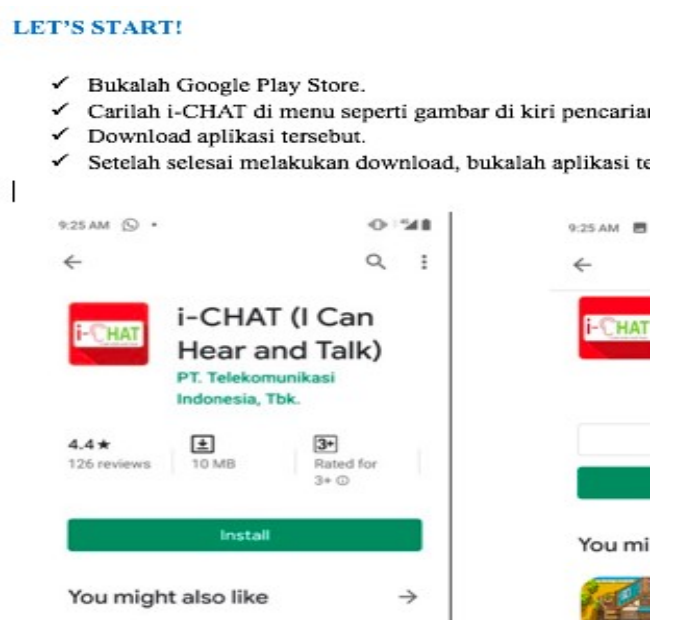

Gambar 2. Halaman Utama untuk Mengunduh Aplikasi i-CHAT

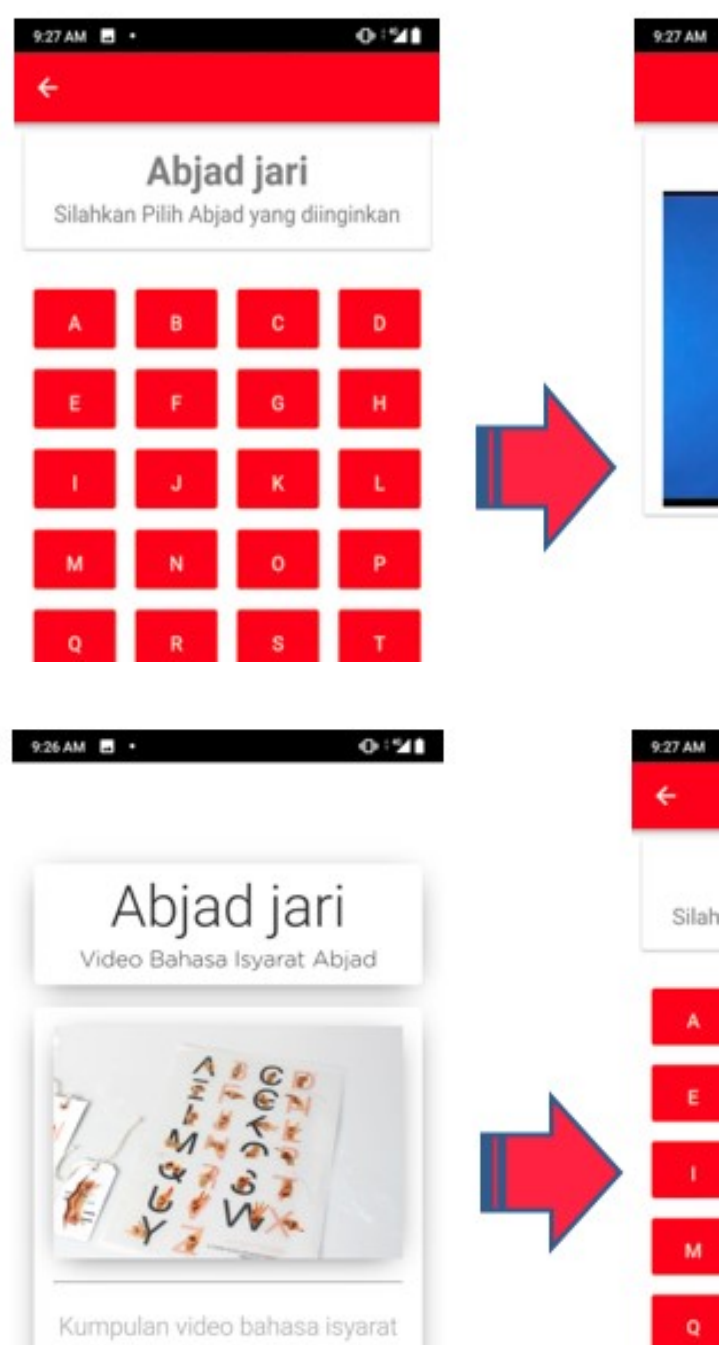

Gambar 3. Materi Pelatihan i-CHAT

Gambar 4 menunjukan liputan pada saat wawancara dan sosialisasi kegiatan bersama koordinator anak-anak panti.

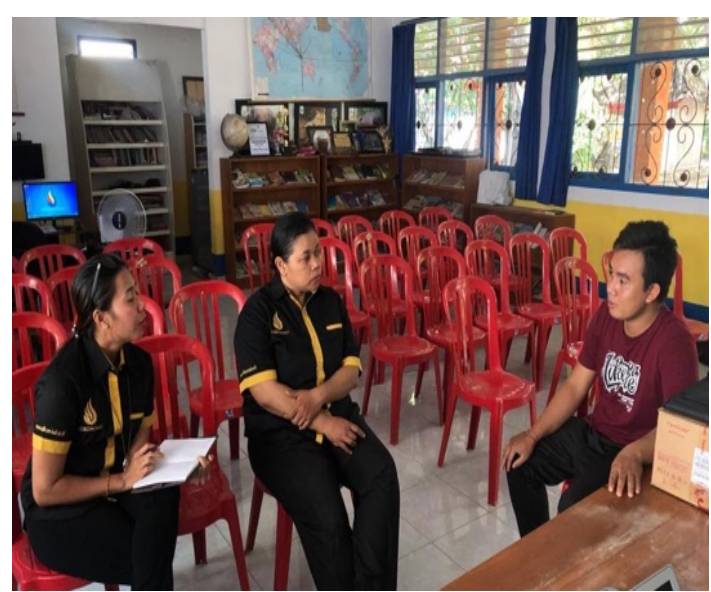

Gambar 4. Wawancara dan Sosialisasi Kegiatan Pengabdian Masyarakat 
Gambar 5 di bawah ini merupakan liputan pada saat sosialisasi aplikasi i-CHAT kepada penghuni panti.

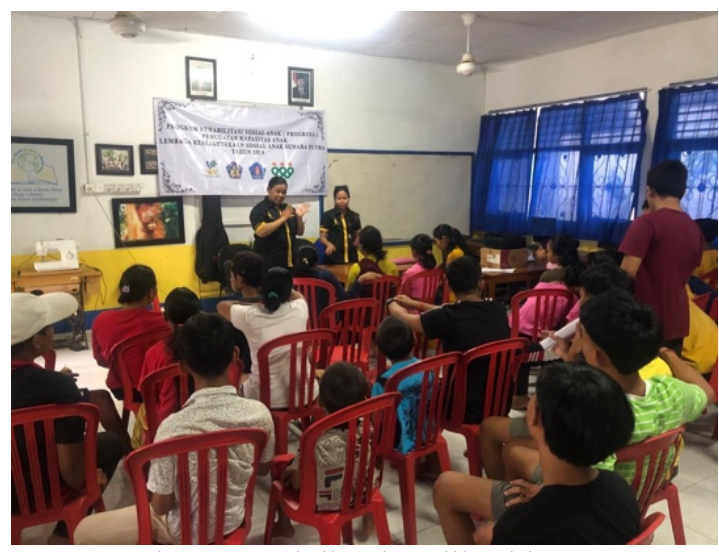

Gambar 5. Sosialisasi Aplikasi i-CHAT

Gambar 6, Gambar 7 dan Gambar 8 merupakan liputan pada saat pelatihan aplikasi i-CHAT itu sendiri, kepada penghuni panti, termasuk $\mathrm{ABK}$ Tuna Rungu.

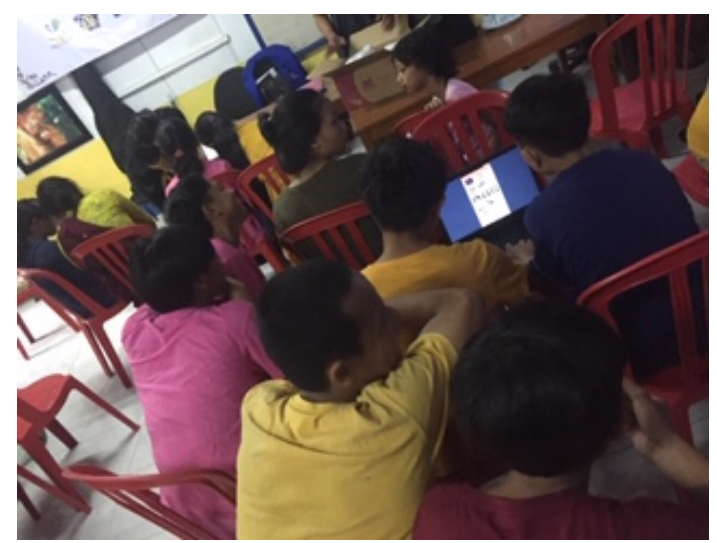

Gambar 6. Pelatihan Aplikasi i-CHAT

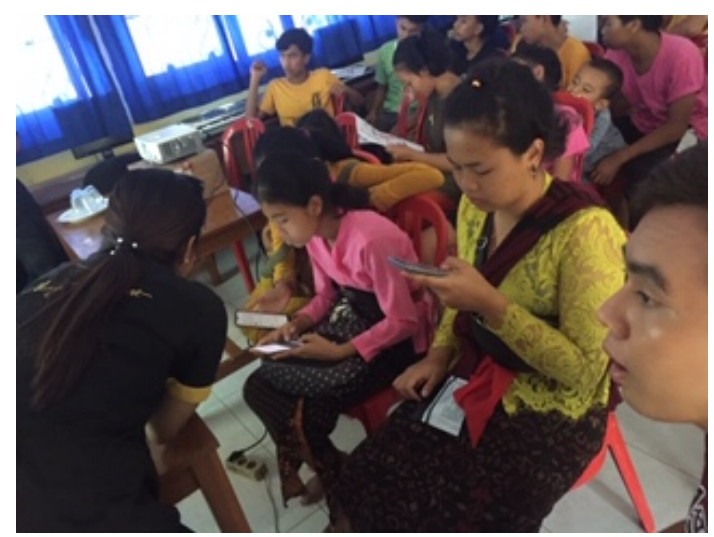

Gambar 7. Ketertarikan ABK pada Pengenalan Aplikasi

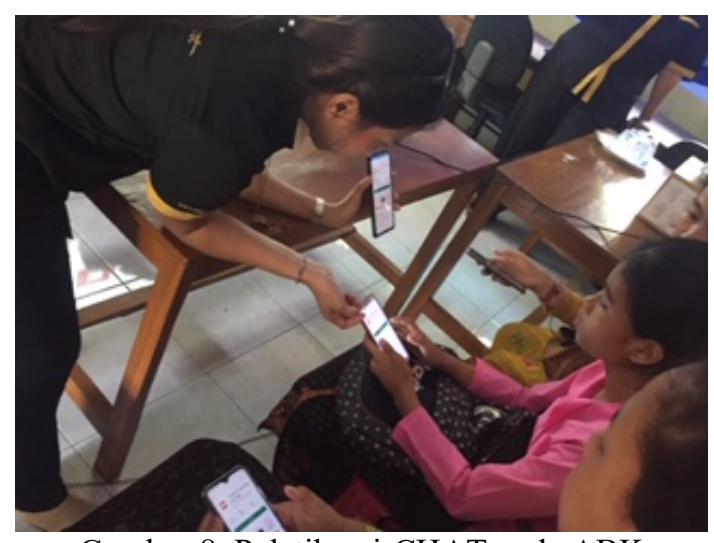

Gambar 8. Pelatihan i-CHAT pada ABK

Gambar 9 adalah sesi photo bersama anakanak Panti Asuhan Semara Putra, sekaligus penutup kegiatan Pengabdian Masyarakat Pengenalan Aplikasi Bahasa Isyarat i-CHAT.

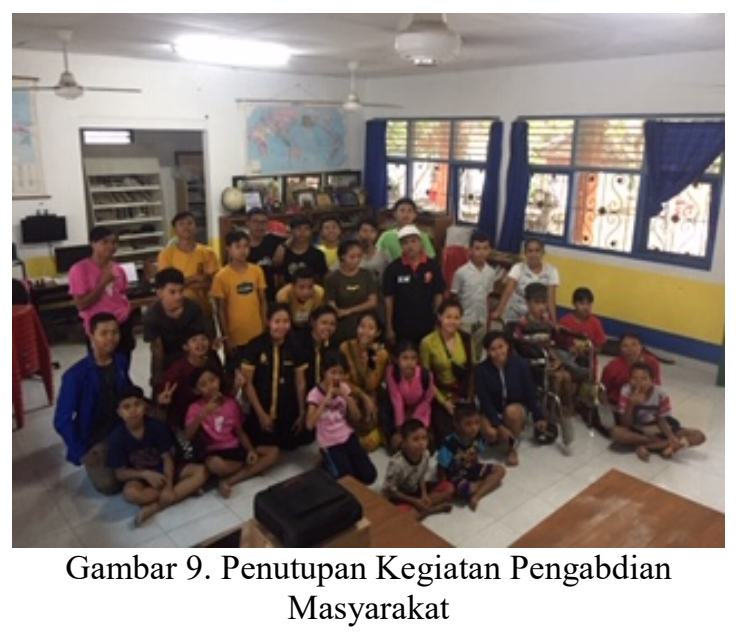

\section{KESIMPULAN}

Hasil kegiatan pengabdian masyarakat ini mengarah kepada kesimpulan bahwa pengenalan dan pelatihan penggunaan aplikasi i-CHAT (I Can Hear and Talk) di panti Asuhan Semara Putra dapat diterima dengan baik oleh ABK Tuna Rungu. Pembelajaran dengan penggunaan multimedia pada aplikasi i-CHAT juga menarik minat mereka. Pengenalan dan pelatihan juga dapat diterima dengan baik oleh anak-anak panti non-ABK. Dengan mengenal dan mendapatkan pelatihan aplikasi i-CHAT, anak-anak non-ABK mampu berkomunikasi dengan baik kepada rekan penghuni panti yang merupakan ABK Tuna Rungu. 
Kemampuan penguasaan Bahasa Isyarat juga dapat membuka kesempatan anakanak non ABK untuk menjadi Penterjemah Bahasa Isyarat bagi yang membutuhkan.

\section{UCAPAN TERIMA KASIH}

Penulis juga mengucapkan terima kasih kepada pihak-pihak yang terlibat; Tim Pelaksana, ITB Stikom Bali serta LPPM ITB Stikom Bali.

\section{DAFTAR PUSTAKA}

Abdullah, N. (2013). Mengenal anak berkebutuhan khusus. Magistra, 25 (86), 1.

Czapanskiy, K. S. (2013). Special kids, special parents, special education. U. Mich. JL Reform, 47, 733.

Desiningrum, D. R. (2017). Psikologi anak berkebutuhan khusus.

Dewanti, P., Pertama, P. P. G. P., \& Indriyani, I. (2019). Pengabdian Masyarakat Pengenalan Internet
Sehat di Panti Asuhan Semara Putra Klungkung. WIDYABHAKTI Jurnal Ilmiah Populer, 1(2), 7-13.

Perempuan, K. P. (2013). Panduan penanganan anak berkebutuhan khusus bagi pendamping (orang tua, keluarga, dan masyarakat). Kementrian Perlindungan Anak dan Perempuan: Jakarta.

Sujatmoko, E. S. (2010). Hak warga negara dalam memperoleh pendidikan. Jurnal Konstitusi, 7 (1), 181-212.

Yanuardi, R., \& Nainggolan, A. W. (2016). I Can Hear And Talk (IChat) As ASEAN Sign Language Computer Application For Hearing Impaired. International Journal of Innovative Research In Technology \& Science (JIRTS), 4(1), 36-40. 